\section{Detection of ureaplasma urealyticum by polymerase chain reaction examination in nonspecific genital infection patients}

\author{
Rahmadewi, Dian PH \\ Department of Dermatology- \\ Venereology, Dr. Soetomo Teaching \\ Hospital / School of Medicine, \\ UniversityAirlangga, Surabaya, \\ Indonesia
}

\begin{abstract}
Non specific genital infection (NSGI) is a condition affecting females which causes inflammation of the endocervix or anterior urethra that is not caused by Neisseria gonorrhoeae. The causative sexually transmitted organisms include Chlamydia trachomatis (Groups D to K) and Ureaplasma urealyticum. Infection caused by Ureaplasma urealyticum is often asymptomatic even though many studies have pronounced that Ureaplasma urealyticum can contribute not only to lower genitourinary infection but also to infertility. Ureaplasma urealyticum cannot be stained by Gram stain due to the lack of a cell wall of the organism. This research aims to evaluate the prevalence of Ureaplasma urealyticum in NSGI patients by using the polymerase chain reaction (PCR) method targeted in the ureaplasma gene structure $429 \mathrm{bp}$ area. The samples were extracted from eighteen DNA NSGI patients. Eleven out of eighteen (61.11\%) DNA NSGI samples tested positive for Ureaplasma urealyticum. Most patients (44.44\%) with Ureaplasma urealyticum were unemployed, and $27.78 \%$ were complaining of recurrent vaginal discharge. The high incidence of Ureaplasma urealyticum in this study needs further attention since doxycycline remains the drug of choice of NSGI. Moxifloxacin should be considered for patients who are making no clinical progress with doxycycline.
\end{abstract}

\section{Introduction}

Non specific genital infection (NSGI) is a condition affecting females which causes inflammation of the endocervix or anterior urethra that not caused by Neisseria onorrhoeae (Hong Kong Social Hygiene Service, 2004). The term non specific is used if the causal organisms cannot be detected by conventional microscopy method. ${ }^{1}$ The causative sexually transmitted organisms include Chlamydia trachomatis (Groups D to K) and Ureaplasma urealyticum gonorrhoeae (Hong Kong Social Hygiene Service, 2004). The prevalence of NSGI at the Outpatient Clinic of Dr. Soetomo General Hospital in 2016 was 47 out of 3,753 new dermatology and venereology cases $(1.25 \%)$. In the Sexually Transmitted Disease Division of the Outpatient Clinic, the percentage of NSGI was $17.22 \%$ (47 out of a total of 273 new cases). Determining the diagnosis of NSGI requires detailed anamnesis of patients and patient's partner's complaints, risk factors and obstetric history. On physical examination, hyperemia, erosion of the cervix and mucopurulent discharge may be found. In microscopy examination from the cervical smear with Gram staining is regarded as positive if 10 to 30 polymorphonuclear leucocytes were seen per high-power field and all other specific bacteria or fungal are not found such as diplococcic Gram negative bacteria (Neisseria gonorrhea), Trichomonas vaginalis, candidiasis vulvovaginalis and bacterial vaginosis. ${ }^{1}$

Based on the literature, Chlamydia trachomatis is the most common $(30 \%-50 \%)$ cause of NSGI, which is inconsistent with the recent study conducted in the Dermatovenereology Outpatient Clinic of Dr. Soetomo General Hospital, Surabaya in 2017. This study found a low incidence $(16.67 \%)$ of Chlamydia trachomatis in eighteen married NSGI patients. ${ }^{2}$ Ureaplasma urealyticum, the second most common cause of NSGI $(10 \%-40 \%)$ is frequently found in the commensal flora of the lower genital tract. $^{2}$ Nevertheless, Ureaplasma species are the most prevalent, potentially pathogenic bacteria isolated from the urogenital tract of both men and women. By evolving from Gram-positive bacteria by degenerative evolution, Ureaplasmas lose their peptidoglycan cell wall. The lack of a cell wall leaves these organisms insensitive to beta lactams, and also prevents the organisms from Gram staining. Ureaplasma has 14 known serotypes and is divided into two groups: Ureplasma parvum (UPA, biovar 1, parvo) and Ureaplasma urealyticum (UUR, biovar 2, T960). In a study conducted by Dhawan B et al, Ureaplasma was found in $25.8 \%$ of patients with genital tract infections and in $20.8 \%$ of infertile women. Previous studies have shown that Ureaplasma urealyticum biovars were associated with pathogenicity. A study by Chua $\mathrm{KB}$ et al, stated that biovar 2 was more associated with the loss of lactobacilli in women than biovar 1 . They verified that biovar 2 was associated with gen-
Correspondence: Rahmadewi, Dermatology Venereology Dept, Faculty of Medicine, Universitas Airlangga - DR Soetomo Teaching Hospital, Jl. Mayjen. Prof. Dr. Moestopo, No. 47, Airlangga, Gubeng, Surabaya, Jawa Timur, 60286.

Telephone: +628123572112

E-mail: dewimbo@yahoo.co.id

Key words: NSGI, Ureaplasma urealyticum, PCR.

Acknowledgements: This study was supported by the RSUD. Dr. Soetomo Teaching Hospital/Medical Faculty of Airlangga University and Institute of Tropical Disease Airlangga University Surabaya.

Contributions: R, Conceived and designed the experiments; DPH, Performed the experiment; R, DPH, Analyzed the data; DPH, Contribution reagens/materials; R, DPH, wrote the paper; DPH, Data collection. Conflict of interest: There are no potential conflicts of interest relevant to this article.

Received for publication: 1 February 2019. Accepted for publication: 12 February 2019.

This work is licensed under a Creative Commons Attribution-NonCommercial 4.0 International License (CC BY-NC 4.0).

(C) Copyright Rahmadewi, Dian PH, 2019 Licensee PAGEPress, Italy

Dermatology Reports 2019; 11(s1):8041 doi:10.4081/dr.2019.8041

itourinary tract infections (58.18\%) compared to biovar 1 , which was only a colonizer of the genitourinary tract. Several clinical reports stated that urogenital infections caused by Ureaplasma urealyticum may cause abnormal pregnancy outcomes by inducing bacterial vaginosis, cervicitis, chorioamnionitis, intrauterine infection, premature rupture of membranes, preterm delivery and neonatal pneumonia.,

Ureaplasmas are susceptible to antimicrobial agents that influence DNA, RNA, protein synthesis or the integrity of the cell membrane; these include tetracyclines, macrolides, chloramphenicol, aminoglycosides and fluroquinolones. However, susceptibility to macrolides is moderate; a recent study indicated that the most common cause of recurrent or persistent urethritis is mixed infection with Mycoplasma genitalium or Ureaplasma urealyticum, particularly among those patients who have been treated with doxycycline, a drug to which Ureaplasma urealyticum or Mycoplasma genitalium may be resistant. ${ }^{1,5,6}$ Tetracycline resistance in Ureaplasma species has been detected and 
resistance is mediated by the tet $\mathrm{M}$ determinant, which encodes a protein that binds to the ribosomes, protecting Ureaplasma spp. from the actions of these drugs. ${ }^{6}$ Abele Horn et al have studied the antibiotic susceptibility of the two Ureaplasma biovars and detected a major resistence to doxycycline and older fluoroquinolones. The resistance rate of the Ureaplasma urealyticum biovar to doxycline was $55 \%$, to ciprofloxacin it was $42 \%$ and to ofloxacin it was $61 \%$. Moxifloxacin was the most active agent in vitro against Ureaplasma urealyticum with the narrowest difference between the minimal inhibitory concentration (MIC) and the minimal bactericidal concentration (MBC) values. Moxifloxacin should be considered for empirical therapy of non-gonococcal non-chlamydial infection, or if the symptoms still persist after gonococcal and/or chlamydial infection has been eradicated. ${ }^{5}$ Hundreds of publications have described various nucleic acid amplification tests (NAATs) and their applications in detecting mycoplasmas and ureaplasmas in clinical specimens since 1989. NAATs are also useful for the identification of organisms grown in culture to the species level, replacing older and less practical technologies. Molecular based methods, such as PCR, are able to detect and identify Ureaplasma urealyticum and Ureaplasma parvum separately, whereas culture cannot do this. ${ }^{7,8}$ PCR has also been adapted to detect antimicrobial resistence determinants and to analyze the genetic relatedness of clinical isolates. ${ }^{7}$ A study by Dhawan et al. established the prevalence of Ureaplasma urealyticum with genital discharge by both culture and PCR. The PCR targeted a 429 bp region in the urease structural gene of Ureaplasma uralyticum. The prevalence of Ureaplasma urealyticum as determined by culture was $32 \%$ while PCR was $45 \%$ with an agreement of $93.75 \% .{ }^{4} \mathrm{PCR}$ seems to be more sensitive for diagnostic purpose compared to culture; PCR detected twenty (15.2\%) more positive samples among 132 clinical specimens compared to culture. ${ }^{8}$

The aim of this study is to discover the incidence of Ureaplasma urealyticum in NSGI patients since it is important to understand the exact causative organism so that precise management can be given to the patients.

\section{Materials and Methods}

This research is a descriptive observational study, using a cross sectional method to evaluate the prevalence of Ureaplasma urealyticum among NSGI patients. This study used the extracted DNA of eighteen NSGI patients that were archived in the Tropical Disease Center (TDC), Universitas Airlangga Surabaya and performed PCR examinations in February 2018. Samples were collected from NSGI patients who came to the Dermatovenereology Outpatient Clinic (Sexual Transmitted Disease Division) of Dr. Soetomo General Hospital, Surabaya, and were taken consecutively for three months (June - August 2017). Inclusion criteria included women with IGNS who are married. Women who were menstruating, pregnant or diagnosed with mixed infection were excluded. Specimen samples were taken from endocervical swab which the diagnosis of NSGI had already established by detailed anamnesis and physical and light microscopy examinations. Informed consent was obtained from the patients prior to procedure.PCR examinations were performed on the DNA of eighteen NSGI patients, extracted from endocervical swabs. The PCR used in this study was MyQ-2 (Bio $\mathrm{Rad})$. The PCR targeted a 429 bp region in the urease structural gene of Ureaplasma urealyticum that is forward strand: 5'ACGAC GTCCA CTG TAAGC AACT-3' and reverse strand: 5'-CAATC TGCTC GTGAA GTATT AC-3'. Ethical clearance had been approved for this study by the Ethical Committee of RSUD Dr. Soetomo General Hospital

\section{Results}

The women diagnosed with NSGI at the Dermatovenereology Outpatient Clinic
(Sexually Transmitted Disease Division) RSUD Dr. Soetomo General Hospital, Surabaya between June and August 2017. The results in this study show that eleven out of eighteen NSGI samples (61.11\%) tested positive for Ureaplasma urealyticum. Of the patients with positive Ureaplasma urealyticum, four patients $(22.22 \%)$ were aged between $17-27$ years old and another four patients $(22.22 \%)$ were in the $28-37$ age group. Most patients (44.44\%) with Ureaplasma urealyticum were unemployed, and $27.78 \%$ were complaining of recurrent vaginal discharge. Table 1 shows the percentage of patients with negative and positive PCR Ureaplasma urealyticum. Figure 1 shows PCR for urease gene of eighteen NSGI samples.

\section{Discussion}

Although Ureaplasma urealyticum is known to be frequently found in the commensal flora of the lower genital tract, this organism is potentially pathogenic isolated from the urogenital tract of both men and women and causes $10 \%-40 \%$ of NSGIs. ${ }^{1,9}$ Some clinical reports declared that urogenital infection caused by Ureaplasma urealyticum can cause chorioamnionitis, spontaneous abortion, stillbirth and preterm abortion during pregnancy. ${ }^{10}$ Ureaplasma has been isolated from patients with pelvic inflammatory disease (PID) affecting fallopian tube; it was also detected in $25.8 \%$ of patients with genital tract infections and $20.8 \%$ of infertile women. ${ }^{9}$

Detection of the exact organisms is important, but the lack of rigid cells makes

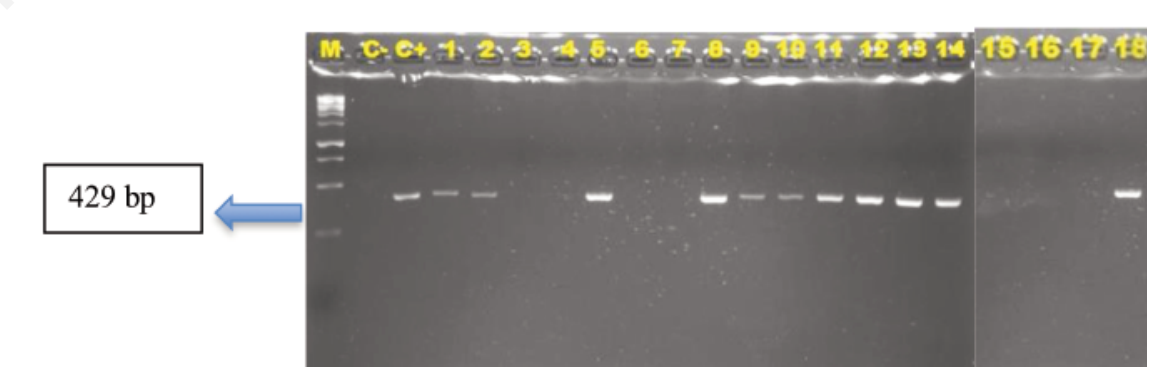

Figure 1. PCR for urease gene, lane 1: $100 \mathrm{bp}$ ladder, lane 2: Ureaplasma urealytcium negative control, lane 3: Ureaplasma urealyticum positive control, numbers $1,2,5,8$ - 14 and 18 show clinical sample positive.

Table 1. Profile result of polymerase chain reaction Ureaplasma urealyticum non specific genital infection.

\begin{tabular}{lcc} 
Result of polymerase chain reaction Chlamydia trachomatis & Total & Percentage (\%) \\
Positive & 11 & 61,11 \\
Negative & 7 & 38,89 \\
\hline Total & 18 & 100 \\
\hline
\end{tabular}


it nearly impossible to directly visualize Ureaplasma by light microscopy, and culture is difficult since these fastidious organisms require the presence of serum, metabolic substrate and growth factors like yeast extract for isolation. ${ }^{9}$ In addition, routine bacterial culture may give negative results for commercial sexual workers or asymptomatic people who have recently experienced unprotected sexual contact and have acquired sexual transmitted infections (STI). These neglected asymptomatic patients in the community can be the reservoir of STIs. ${ }^{11}$ The identification of the specific organism leads the clinician to make precise management of the infections so that no complication will occur. Currently, the focus is on syndromic management, which is not a very sensitive or specific method for establishing diagnosis of upper genital infection. Furthermore, because of ever increasing drug resistance, it is better to diagnose and treat the specific causative organism as far as this is possible. In a study involving patients with infertility and genital discharge, Ureaplasma spp. 91\% were susceptible to doxycycline, $77 \%$ to ofloxacin, and $71 \%$ to azithromycin. ${ }^{4}$ Govender and Chalkley mentioned nine tetracycline-resistant strains concurrently resistant to doxycycline. Another study by Kenny and Cartwright stated Ureaplasmas were susceptible to quinolones with the highest activities being shown by moxifloxacin and sparfloxacin. ${ }^{12,13}$ Most pathogens causing STI as well as commensal microorganisms are difficult to cultivate by routine microbiological diagnosis. NAATs, such as PCR, are useful for the identification of microorganisms that are difficult to cultivate and for those that grow slowly. ${ }^{4}$ The present study used PCR and targeted a 429 bp region in the urease structural gene of Ureaplasma urealyticum that is forward strand: 5'-ACGAC GTCCA CTG TAAGC AACT-3' and reverse strand: 5'-CAATC TGCTC GTGAA GTATT AC3'. The samples used in this study were the extracted DNA of eighteen NSGI patients.

The results of this study performed in TDC Universitas Airlangga Surabaya and the sample specimens collected in Dr. Soetomo General Hospital, Surabaya, determined that eleven out of eighteen NSGI patients $(61.11 \%)$ were detected Ureaplasma urealyticum, using the PCR method. This prevalence was in keeping with the study by Peerayeh et al on infertile women with endocervical specimens, which found that $51.7 \%$ tested positive for Ureaplasma urealyticum by the PCR method. Our study also found four patients $(22.22 \%)$ were aged between $28-37$ years, which is comparable to the study by Peerayeh et al, which found that
$20.7 \%$ of patients with Ureaplasma urealyticum were aged $28-37 .{ }^{12}$ There is no previous study that has been performed in similar populations. ${ }^{14}$

\section{Conclusions}

To determine the specific causative organism of NSGI is important, due to the severe complications that may be caused. The increasing resistance of tetracycline in Ureaplasma strains requires careful antimicrobial preferences. This study may prove useful in providing information on the prevalence of Ureaplasma urealyticum and the management of NSGI caused by non chlamydial infection. The high incidence of Ureaplasma urealyticum in this study needs further attention since doxycycline remains the drug of choice of NSGI. Moxifloxacin should be considered for patients who are making no clinical progress with doxycycline. Research concerning the susceptibilities and resistances of Ureaplasma urealyticum to antimicrobial classes such as macrolides, tetracyclines and quinolones may also need to be undertaken.

\section{References}

1. Murtiastutik, D., Widyantari, S., Lumintang, H. Infeksi genital non spesifik. In: Daili, S.F., Nilasari, H., Makes, W.I.B., Zubier, F., Romawi, R., Pudjiati, S.R., editor. Infeksi Menular Seksual. Jakarta 2017; Fakultas Kedokteran Indonesia 5 pp 88-101.

2. Habibie, D.P., Murtiastutik, D., Rahmadewi. Pemeriksaan polymerase chain reaction (PCR) Chlamydia trachomatis pada pasien Infeksi genital non spesifik. Departemen/SMF Ilmu Kesehatan Kulit dan Kelamin, FK Universitas Airlangga, RSUD Dr. Soetomo Surabaya 2017. (thesis)

3. Harada, K., Tanaka, H., Komori, S., Tsuji, Y., Nagata, K., Tsutsui, H., Koyama, K. Vaginal infection with Ureaplasma urealyticum accounts for preterm delivery via induction of inflammatory responses. Microbiology and Immunology 2008;52:297-304.

4. Dev, T., Taneja, N., Juyal, D., Dhawan, B., Gupta, S. Upper genital tract infection due to Ureaplasma urealyticum: etiological or syndromic management? IJDVL 2017; 83(4):489-91.

5. Samra, Z., Rosenberg, S., Dan, M. Susceptibility of Ureaplasma urealyticum to tetracycline, doxycycline, erythromycin, roxithromycin, clar- ithromycin, azithromycin, levofloxacin and moxifloxacin. Journal of chemotherapy (Florence, Italy) 2011;23:77-79.

6. Totten, P.A., Robinson, D.T., Jensen, J.S. 2008. Genital Mycoplasmas. In: Holmes, K.K., Sparling, P.F., Stamm, W.E., Piot, P., Wasserheit, J.N., Corey, L. Sexually transmited disease. Fourth edition. New York;McGraw Hill Medical; 2008. p.709-36.

7. Waites, K.B., Xiao, L., Paralanov, V., Viscardi, R.M., Glass, J.I. Molecular methods for the detection of mycoplasma and ureaplasma infections in humans: A paper from the 2011 William Beaumont Hospital symposium on molecular pathology. J Molecul Diagnostics 2012.

8. Marovt, M., Keše, D., Miljković, J., Mactičič, M. Clinical role of Ureaplasma parvum and Ureaplasma urealyticum presence in female lower urogenital tract: is there a place for routine screening and treatment?. Zdrav Vestn 2014;83:629-37.

9. Kokkayil, P., Dhawan, B. Ureaplasma: current perspective. Indian $\mathrm{J}$ Med Microbiol 2015;33, 205-14.

10. Lee, M.Y., Kim, M.H., Lee, W.I., Kang, S.Y., Jeon, Y.L. Prevalence and antibiotic susceptibility of mycoplasma hominis and ureaplasma urealyticum in pregnant women. Yonsei Medical Journal 2016;57:1271-1275.

11. Kim, S.-J., Lee, D.S., Lee, S.-J., 2011. The Prevalence and Clinical Significance of Urethritis and Cervicitis in Asymptomatic People by Use of Multiplex Polymerase Chain Reaction. Korean Journal of Urology (C) The Korean Urological Association Korean J Urol 2011;52:703-708.

12. Kenny, G.E., Cartwright, F.D. Susceptibilities of Mycoplasma hominis, M. pneumoniae, and Ureaplasma urealyticum to GAR-936, dalfopristin, dirithromycin, evernimicin, gatifloxacin, linezolid, moxifloxacin, quinupristin-dalfopristin, and telithromycin compared to their susceptibilities to reference macrolides, tetracyclines, and quinolones. Antimicrobial Agents and Chemotherapy 2001;45:2604-2608.

13. Govender, S., Chalkley, L.J. Tetracycline resistance genes of ureaplasmas. South Afr J Epidemiol Infect 2012;27(1):19-23.

14. Peerayeh, S.N., Sattari, M. Detection of Ureaplasma uealyticum and Mycoplasma hominis in endocervical specimens from infertile women by polymerase chain reaction. MEFSJ 2006;2(11):104-8. 